\title{
Fire resistance of stainless steel slender cross-sections under bending and axial compression
}

\author{
F. Arrais, N. Lopes \& P. Vila Real \\ RISCO, Department of Civil Engineering, University of Aveiro, Aveiro, Portugal
}

\begin{abstract}
Stainless steel has different advantages when compared to conventional carbon steel. The corrosion resistance and aesthetic appearance are the most known, but its higher fire resistance can also be decisive. With its increased use, the validation of existing design rules, for structural elements made of this material, becomes urgent. In order to have a comprehensive understanding of the overall thin-walled members' fire resistance, it is important to first analyse the cross-section resistance at elevated temperatures, which is directly affected by local instabilities occurrence on the composed thin plates. This work presents a numerical study on the behaviour of stainless steel slender cross-sections under bending and under axial compression at elevated temperatures, with the purpose of evaluating the accuracy of Eurocode 3 design formulations for the effective section calculation. The obtained numerical results are compared with the Eurocode prescriptions and with a recently proposed method, concluding that the design methodologies should be improved for rectangular hollow profiles.
\end{abstract}

\section{INTRODUCTION}

The application of stainless steel as a structural material has been increasing, due to a number of desirable qualities such as its durability, resistance to corrosion and aesthetic appearance (Gardner, L., 2005 \& Euro Inox, 2006). Despite having a high initial cost, stainless steel can be a competitive material if life cycle cost analysis is considered, due to its low maintenance needs. Moreover, it has a higher fire resistance when compared to carbon steel (CEN, 2005b) allowing in some cases the absence of thermal protection.

The austenitic stainless steels are generally the most used groups for structural applications but some interest has been recently shown for increasing the use of ferritic and austeniticferritic (Duplex) steels for structural purposes due to specific advantages. Some of those advantages are the very good resistance to wear and stress corrosion cracking of the duplex grade and the lower percentage of Nickel of the ferritic grade, which reduces its price.

Regarding structural design, Eurocode 3 (EC3) (CEN, 2006a) considers that the walls slenderness determine the cross-section classification (Class 1 - stocky sections to Class 4 - slender sections).

Although the subject of local buckling at elevated temperatures has been studied by different authors (Couto et al., 2014, Couto et al., 2015, FIDESC4, 2014, Knobloch \& Fontana, 2006, Maraveas et at., 2017, Quiel \& Garlock, 2010), they have only addressed elements in carbon steel, and research of the local buckling effect on stainless steel sections at elevated temperatures has just started to be developed (Xing et al., 2020), focused on I-sections.

According to EN 1993-1-2 (CEN, 2005b), stainless steel stress-strain relationships at high temperatures are characterized by having a non-linear behaviour with an extensive hardening phase, when compared with carbon steel constitutive law. As existing fire design rules for stainless steel, such as in EN 1993-1-2 (CEN, 2005b), are based on the formulations developed for carbon steel 
members (CEN, 2005a, CEN, 2006b) in spite of the different material behaviour, it is still necessary to develop knowledge on stainless steel structural behaviour at high temperatures.

This work presents a numerical study on the behaviour of stainless steel slender crosssections under bending and under axial compression at elevated temperatures. I-sections and Rectangular Hollow Sections (RHS) are analysed with the purpose of evaluating the accuracy of EC3 design formulations (CEN, 2005b) for the reduction of the widths of each crosssection element (internal elements in hollow sections, or internal and outstand elements in I-sections), according to the effective width method. Although EC3 uses the concept of simply supported plates for the effective width method, not differentiating between I-sections and RHS. The disposition of the different elements on these two cross-section types provides different restriction degrees (restrictions to rotation) to the corresponded plates, which might influence the cross-section resistance.

A parametric study considering different stainless steel grades (such as Austenitic, Ferritic and Duplex, which have different constitutive laws), cross-section slenderness, uniform elevated temperatures (from $350{ }^{\circ} \mathrm{C}$ to $700{ }^{\circ} \mathrm{C}$ ) and loading conditions (compression and bending) is presented. The study was conducted applying geometrically and materially nonlinear analyses including imperfections (GMNIA), using the SAFIR ${ }^{\circledR}$ finite element program (Gernay \& Franssen, 2017).

Comparisons between the numerically obtained ultimate bearing capacities of the tested cross-sections, the EC3 design methods and the application of a recent proposal for slender stainless steel plates (Xing et al., 2020), are made.

\section{FIRE DESIGN RULES}

According to EN 1993-1-2 (CEN, 2005), the section resistance of a stainless steel member in case of fire is calculated in the same way as for carbon steel, changing only the mechanical properties of the material. Regarding the cross-section classification, equation (1) is used to determine $\varepsilon_{f i}$, a parameter necessary for the determination of the EC3 classification limits (Franssen \& Vila Real, 2015):

$$
\varepsilon_{f i}=0.85\left[\frac{235}{f_{y}} \frac{E}{210000}\right]^{0.5}
$$

The cross-section resistance value of axially compressed members of Class 1, 2 or 3 crosssections with a uniform temperature, should be determined from equation (2):

$$
N_{f i, \theta, R d}=A f_{y, \theta} / \gamma_{M, f i}
$$

For Class 4 cross-sections, according to Annex E of EN 1993-1-2, the effective area $\left(A_{\text {eff }}\right)$ should be considered instead of the gross cross-section area, determined with the effective section properties obtained from EN 1993-1-5 at normal temperature. In fire situation, higher strains are acceptable when compared to normal temperature design. Therefore, instead of $0.2 \%$ proof strength usually considered at normal temperature, for cross-sections of Class 1,2 and 3 at elevated temperatures the stress corresponding to $2 \%$ total strain should be adopted as the yield strength, equation (3):

$$
f_{y, \theta}=f_{2, \theta}=k_{2, \theta} f_{y}
$$

Being the $0.2 \%$ proof strength used for Class 4 cross-sections:

$$
f_{y, \theta}=f_{p 0.2, \theta}=k_{p 0.2, \theta} f_{y}
$$


Table 1. Reduction factor for stainless steel sections elements.

\begin{tabular}{llll}
\hline Cross-section elements & \multicolumn{2}{l}{ Reduction factor } \\
\hline Welded outstand elements & $\rho=\frac{1}{\bar{\lambda}_{\mathrm{p}}}$ & $\frac{0.242}{\bar{\lambda}_{\mathrm{p}}^{2}}$ & 1 \\
Welded internal elements & $\rho=\frac{0.772}{\bar{\lambda}_{\mathrm{p}}}$ & $\frac{0.125}{\overline{\bar{\lambda}}_{\mathrm{p}}^{2}}$ & 1 \\
\hline
\end{tabular}

The respective yield strength reduction factors are presented in Annex C of EN 1993-1-2.

In beams, the design value of the bending moment resistance of a cross-section with a uniform temperature shall be determined from:

$$
M_{f i, \theta, R d}=W_{y} f_{y, \theta} / \gamma_{M, f i}
$$

Being $W_{y}$ for Classes 1 and 2 the plastic section modulus, $W_{p l, y}$, for Class 3 the elastic section modulus, $W_{e l, y}$, and for Class 4 sections the effective section modulus, $W_{e f f, y}$, at normal temperature, determined with the effective section properties obtained from EN 1993-1-5. The effective area and effective section modulus are determined through the application of the effective width method, considering the reduction of resistance due to local buckling effects (CEN, 2006b). In this regard, EN 1993-1-4 (CEN, 2006a) provides specific equations for the determination of the plate reduction factors to the width of elements composing the stainless steel sections (Table 1).

The plate slenderness $-\bar{\lambda}_{\mathrm{p}}-$ value is determined with equation (6):

$$
\bar{\lambda}_{\mathrm{p}}=\sqrt{\frac{f_{y}}{\sigma_{c r}}}=\frac{\bar{b} / t}{28.4 \varepsilon \sqrt{k_{\sigma}}}
$$

Xing et al. (2020) considers the use of the stress corresponding to $2 \%$ of total strain for the stainless steel yield strength of Class 4 cross-sections at elevated temperatures, as it is done for the remaining sections, providing the plate reduction factors to be calculated as presented in Table 2.

\begin{tabular}{|c|c|c|}
\hline Cross-section elements & Stainless steel grade & Reduction factor \\
\hline \multirow[t]{3}{*}{ Outstand elements } & Austenitic & $\rho=1.0$ for $\bar{\lambda}_{\mathrm{p}, \theta} \leq \bar{\lambda}_{\mathrm{p} 0, \theta}$ \\
\hline & & $\begin{array}{l}\rho=\frac{0.6}{\left(\bar{\lambda}_{\mathrm{p}, \theta} / \sqrt{\xi_{\theta}}\right)}-\frac{0.075}{\left(\bar{\lambda}_{\mathrm{p}, \theta} / \sqrt{\xi_{\theta}}\right)} \text { for } \bar{\lambda}_{\mathrm{p}, \theta}>\bar{\lambda}_{\mathrm{p} 0, \theta} \\
\bar{\lambda}_{\mathrm{p} 0, \theta}=0.237 \sqrt{\xi_{\theta}}\end{array}$ \\
\hline & Ferritic and Duplex & $\begin{array}{l}\rho=1.0 \text { for } \bar{\lambda}_{\mathrm{p}, \theta} \leq \bar{\lambda}_{\mathrm{p} 0, \theta} \\
\rho=\frac{0.67}{\left(\overline{\mathrm{p}}_{\mathrm{p}, \theta} / \sqrt{\xi_{\theta}}\right)^{0.6}}-\frac{0.075}{\left(\bar{\lambda}_{\mathrm{p}, \theta} / \sqrt{\xi_{\theta}}\right)} \text { for } \bar{\lambda}_{\mathrm{p}, \theta}>\bar{\lambda}_{\mathrm{p} 0, \theta} \\
\bar{\lambda}_{\mathrm{p} 0, \theta}=0.344 \sqrt{\xi_{\theta}}\end{array}$ \\
\hline \multirow[t]{2}{*}{ Internal elements } & Austenitic & $\begin{array}{l}\rho=1.0 \text { for } \bar{\lambda}_{\mathrm{p}, \theta} \leq \bar{\lambda}_{\mathrm{p} 0, \theta} \\
\rho=\frac{0.54}{\left(\bar{\lambda}_{\mathrm{p}, \theta} / \sqrt{\xi_{\theta}}\right)^{0.75}}-\frac{0.015(3+\psi)}{\left(\bar{\lambda}_{\mathrm{p}, \theta} / \sqrt{\xi_{\theta}}\right)^{1.5}} \text { for } \bar{\lambda}_{\mathrm{p}, \theta}>\bar{\lambda}_{\mathrm{p} 0, \theta} \\
\bar{\lambda}_{\mathrm{p} 0, \theta}=(0.27+\sqrt{0.0279-0.015 \psi})^{1.33} \sqrt{\xi_{\theta}}\end{array}$ \\
\hline & Ferritic and Duplex & $\begin{array}{l}\rho=1.0 \text { for } \bar{\lambda}_{\mathrm{p}, \theta} \leq \bar{\lambda}_{\mathrm{p} 0, \theta} \\
\rho=\frac{0.6}{\left(\bar{\lambda}_{\mathrm{p}, \theta} / \sqrt{\xi_{\theta}}\right)^{0.75}}-\frac{0.015(3+\psi)}{\left(\bar{\lambda}_{\mathrm{p}, \theta} / \sqrt{\xi_{\theta}}\right)^{1.5}} \text { for } \bar{\lambda}_{\mathrm{p}, \theta}>\bar{\lambda}_{\mathrm{p} 0, \theta} \\
\bar{\lambda}_{\mathrm{p} 0, \theta}=(0.3+\sqrt{0.045-0.015 \psi})^{1.33} \sqrt{\xi_{\theta}}\end{array}$ \\
\hline
\end{tabular}

Table 2. Reduction factor for stainless steel slender sections elements proposed by Xing et al. (2020). 
The relative elevated temperature slenderness $\bar{\lambda}_{\mathrm{p}, \theta}$ is determined as $\bar{\lambda}_{\mathrm{p}, \theta}=\xi_{\theta} \bar{\lambda}_{\mathrm{p}}$ with the elevated temperature factor $\xi_{\theta}=\sqrt{k_{2, \theta} / k_{E, \theta}}$ (with $\psi$ the ratio between the end moments $(-1 \leq \psi \leq 1)$.

\section{CASE STUDY AND NUMERICAL MODELLING}

A parametric study was developed based on finite element analysis to determine and compare the ultimate bearing capacity of I-section and RHS subjected to compression or bending. The results determined with EC3 formulae and with the new proposal for stainless steel sections in fire (Xing et al., 2020) are compared to the numerical ultimate cross-sectional bearing capacity.

The I-sections and RHS considered in this study have equivalent webs that are always Class 4 (slender), being the flanges of Class 1 . The I-sections had $150 \mathrm{~mm}$ height and $140 \mathrm{~mm}$ width, varying the thicknesses for both cross-section types and the RHS were analysed as welded box sections with $150 \mathrm{~mm}$ height and $100 \mathrm{~mm}$ width. These restrained members had $1 \mathrm{~m}$ length. The stainless steel grades austenitic (1.4301), ferritic (1.4003) and duplex (1.4462) were considered in the study at the temperatures of $350{ }^{\circ} \mathrm{C}, 500{ }^{\circ} \mathrm{C}, 600{ }^{\circ} \mathrm{C}$ and $700{ }^{\circ} \mathrm{C}$.

In the finite element models (Figure 1), rectangular shell finite elements with four nodes, with six degrees of freedom (three translations and three rotations), of $10 \mathrm{~mm}$ length over the member cross-section at flat plates, are used. During all the analysis the end-plates were at normal temperature and had 10 times the thickness of the thickest element's wall. In the longitudinal direction, the mesh size is $10 \mathrm{~mm}$. Loads in the parallel direction to the members axis were applied on the nodes of the members ends, according to the linear stresses distribution resulting from simple bending around the strong axis or axial compression. Restrictions are applied to reproduce hinged supports and to restrain the out-of-plane buckling. This study did not consider the residual stresses as they exhibit low influence at elevated temperatures.

The shapes obtained from local buckling modes, applying CAST3M program (CEA, 2012) together with the RUBY interface (Couto et al., 2013), were used to define the initial geometric imperfections. According to Annex C of EN 1993-1-5 (CEN, 2006b), the geometric imperfections' magnitudes were obtained from $80 \%$ of the prescribed geometric manufacturing tolerances: $0.8 b / 200$ (for $b / t \leq 80$ ) or $0.8 b^{2} /(16000 t$ ) (for $80<b / t \leq 200$ ) or $0.8 b / 80$ (for $b / t>200$ ) (being always higher than the thickness) as local imperfection for I-sections, according to EN 1090-2 (CEN, 2018); and 0.8b/100 as local imperfection for RHS obtained from EN 10219-2 (CEN, 2019), where $b$ is the length of the web or flange, depending on the highest deformation value.

a)

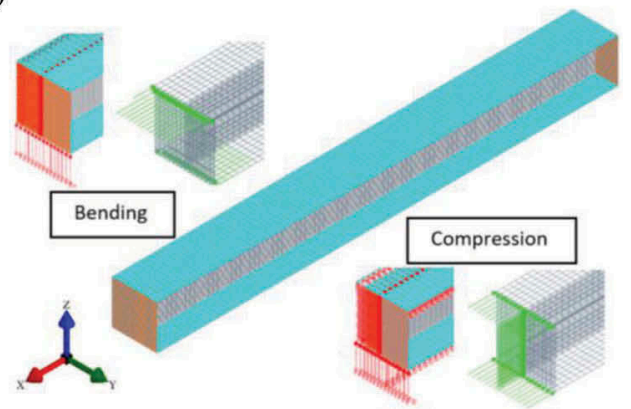

b)

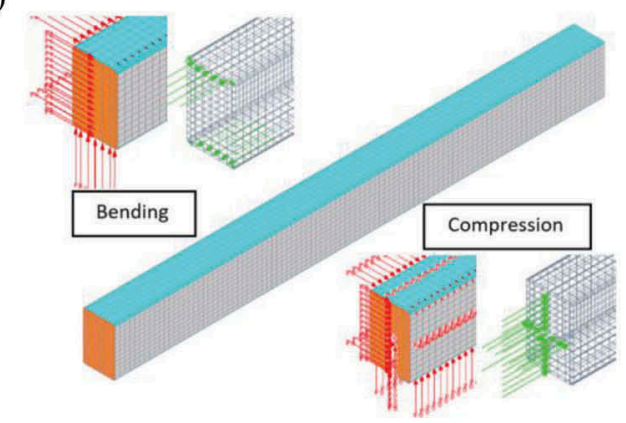

Figure 1. Numerical models adopted and respective loads and restrictions. a) I-section model, b) RHS model. 


\section{COMPARISON BETWEEN NUMERICAL RESULTS AND FIRE DESIGN RULES}

This section presents the parametric study results. The numerically obtained ultimate bearing load capacities were compared with the calculation rules of EN 1993-1-2 (Figure 2) and Xing et al. (2020) proposal (Figure 3). Figure 4 presents collapse modes examples obtained from the numerical analysis for I-section and RHS members under axial compression.

With the validation criteria proposed by Kruppa (1999), Table 3 presents the statistical evaluation for bending based on a total of 240 numerical results and Table 4 for axial compression based on a total of 336 numerical results, both tables considering all stainless steel grades results.

a)

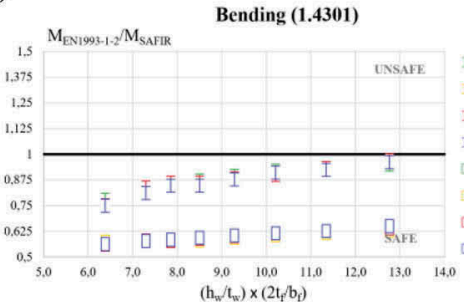

b)

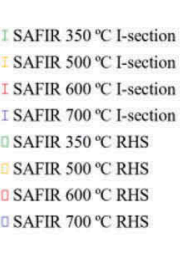

Figure 2. Comparison between the EN1993-1-2 and the numerical results, at elevated temperatures, for austenitic stainless steel cross-sections under a) bending and b) axial compression.

a)

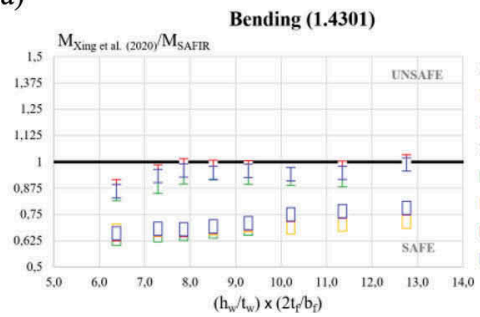

b)

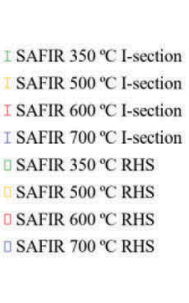

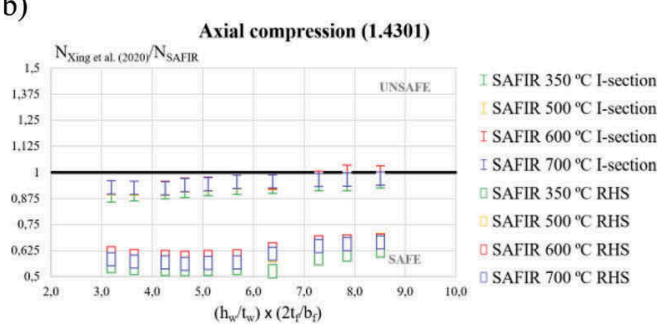

Figure 3. Comparison between the new proposal of Xing et al. (2020) and the numerical results, at elevated temperatures, for austenitic stainless steel cross-sections under a) bending and b) axial compression.

a)

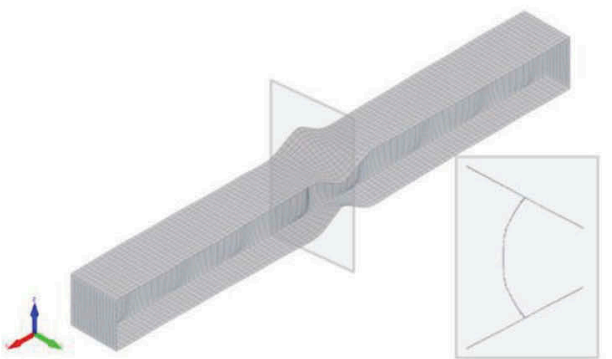

b)

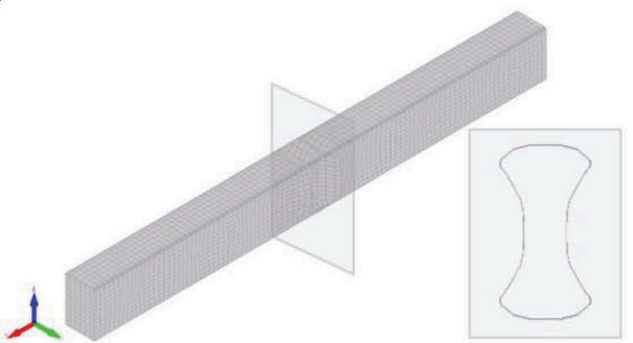

Figure 4. Example of numerical collapse mode obtained for a) I-section and for b) RHS under axial compression at elevated temperatures. 
Table 3. Statistical evaluation with bending results considering the different stainless steel grades.

\begin{tabular}{|c|c|c|c|c|c|c|c|c|c|c|c|c|}
\hline \multirow[b]{2}{*}{ Bending } & \multicolumn{4}{|c|}{ Austenitic } & \multicolumn{4}{|c|}{ Ferritic } & \multicolumn{4}{|c|}{ Duplex } \\
\hline & $\mu$ & $s$ & Max. & $\begin{array}{l}\% \\
\text { Uns. }\end{array}$ & $\mu$ & $s$ & Max. & $\begin{array}{l}\% \\
\text { Uns. }\end{array}$ & $\mu$ & $s$ & Max. & $\begin{array}{l}\% \\
\text { Uns. }\end{array}$ \\
\hline EN1993-1-2 (I) & 0.876 & 0.060 & 0.970 & 0.0 & 0.702 & 0.022 & 0.723 & 0.0 & 0.850 & 0.046 & 0.901 & 0.0 \\
\hline Xing et al. (I) & 0.951 & 0.044 & 1.009 & 7.7 & 0.759 & 0.029 & 0.813 & 0.0 & 0.859 & 0.034 & 0.927 & 0.0 \\
\hline $\begin{array}{l}\text { EN1993-1-2 } \\
\text { (RHS) }\end{array}$ & 0.602 & 0.026 & 0.656 & 0.0 & 0.543 & 0.048 & 0.644 & 0.0 & 0.564 & 0.050 & 0.630 & 0.0 \\
\hline $\begin{array}{l}\text { Xing et al. } \\
\text { (RHS) }\end{array}$ & 0.701 & 0.039 & 0.781 & 0.0 & 0.674 & 0.064 & 0.788 & 0.0 & 0.694 & 0.054 & 0.796 & 0.0 \\
\hline
\end{tabular}

Table 4. Statistical evaluation with axial compression results considering the different stainless steel grades.

\begin{tabular}{|c|c|c|c|c|c|c|c|c|c|c|c|c|}
\hline \multirow[b]{2}{*}{ Compression } & \multicolumn{4}{|c|}{ Austenitic } & \multicolumn{4}{|c|}{ Ferritic } & \multicolumn{4}{|c|}{ Duplex } \\
\hline & $\mu$ & $s$ & Max. & $\begin{array}{l}\% \\
\text { Uns. }\end{array}$ & $\mu$ & $s$ & Max. & $\begin{array}{l}\% \\
\text { Uns. }\end{array}$ & $\mu$ & $s$ & Max. & $\begin{array}{l}\% \\
\text { Uns. }\end{array}$ \\
\hline EN1993-1-2 (I) & 0.880 & 0.037 & 0.960 & 0.0 & 0.780 & 0.040 & 0.859 & 0.0 & 0.845 & 0.039 & 0.965 & 0.0 \\
\hline Xing et al. (I) & 0.944 & 0.028 & 1.003 & 7.5 & 0.820 & 0.044 & 0.916 & 0.0 & 0.889 & 0.959 & 1.000 & 2.3 \\
\hline $\begin{array}{l}\text { EN1993-1-2 } \\
\text { (RHS) }\end{array}$ & 0.534 & 0.029 & 0.593 & 0.0 & 0.616 & 0.030 & 0.658 & 0.0 & 0.604 & 0.031 & 0.657 & 0.0 \\
\hline $\begin{array}{l}\text { Xing et al. } \\
\text { (RHS) }\end{array}$ & 0.595 & 0.045 & 0.674 & 0.0 & 0.729 & 0.038 & 0.768 & 0.0 & 0.695 & 0.044 & 0.757 & 0.0 \\
\hline
\end{tabular}

From these comparisons, it can be concluded that both approaches are mostly on the safety side for I-sections and the results are relatively well adapted for Xing et al., 2020 proposal highlighting the results of the austenitic stainless steel (as also demonstrated in Figures 3 and 4). For RHS the methodologies are also safe, however over conservative specially compared to EN 1993-1-2 design rules, due to the stiffness provided by the flanges, that are in RHS internal elements, to the slender webs.

\section{CONCLUSIONS}

This research presented a parametric study on the cross-sectional resistance of stainless steel slender I-sections and Rectangular Hollow Sections (RHS) at elevated temperatures of members under bending and under axial.

A comparison was made between the ultimate load bearing capacities obtained numerically and the requirements of EC3 and Xing et al. (2020) proposal, leading to the conclusion that both design methodologies are too conservative for RHS. It was also possible to observe that Xing et al. (2020) proposal presents a better approximation to the I-section numerical results when compared to EC3. Further studies will help to develop more precise design formulae for RHS, following the format of the proposed approaches.

\section{ACKNOWLEDGEMENTS}

This research was performed within the framework of the project "StaSteFi - Fire design of stainless steel members", PTDC/ECI-EGC/30655/2017, supported by the Portuguese Operational Programme "Competitividade e Internacionalização", in its FEDER/FNR component, and the Portuguese FCT, in its State Budget component (OE). 


\section{REFERENCES}

CAST3M, sponsored by French Atomic Energy Commission; 2012. http://www-cast3m.cea.fr/

CEN - EN 1993-1-1, Eurocode 3: Design of steel Structures - Part 1-1: General rules and rules for buildings, Belgium, 2005a.

CEN - EN 1993-1-2, Eurocode 3: Design of Steel Structures - Part 1-2: General rules - Structural fire design, Belgium, 2005b.

CEN - EN 1993-1-4, Eurocode 3: Design of steel Structures - Part 1-4: General rules - Supplementary Rules for Stainless steels, Belgium, 2006a.

CEN - EN 1993-1-5, Eurocode 3: Design of Steel Structures - Part 1-5: Plated structural elements, Belgium, 2006b.

CEN - EN 1090-2, Execution of steel structures and aluminium structures - Part 2: Technical requirements for the execution of steel structures, Belgium, 2018.

CEN - EN 10219-2, Cold Formed Welded Steel Structural Hollow Sections - Part 2: Tolerances, Dimensions and Sectional Properties, Belgium, 2019

Couto, C., Vila Real, P., Lopes, N., RUBY - an interface software for running a buckling analysis of SAFIR models using Cast3M, University of Aveiro, 2013.

Couto, C., Vila Real, P., Lopes, N. \& Zhao, B., Effective width method to account for the local buckling of steel thin plates at elevated temperatures. Thin-Walled Structures, 84, 2014, 134-149.

Couto, C., Fire design of steel members with class 4 cross-section, $\mathrm{PhD}$ thesis, University of Aveiro, Portugal, 2015.

Euro Inox, SCI, Design Manual for Structural Stainless Steel, 3rd edition, 2006.

FIDESC4, Fire Design of Steel Members with Welded or Hot-Rolled Class 4 Cross-Section, RFCS-CT -2011-2014, Technical Report No. 5, 2014.

Franssen, J-M. \& Vila Real, P., Fire Design of Steel Structures, ECCS, Ernst \& Sohn, a Wiley Company, 2nd edition, 2015.

Gardner, L. 2005. The use of stainless steel in structures. Progress in Structural Engineering and Materials, vol 7, pp 45-55.

Gernay, T., Franssen, J.M., Modelling structures in fire with SAFIR®: Theoretical background and capabilities, Journal of Structural Fire Engineering, Vol. 8, issue 3, 2017, pp. 300-323.

Knobloch, M., \& Fontana, M., Strain-based approach to local buckling of steel sections subjected to fire, Journal of Constructional Steel Research, 62(1-2), 2006, 44-67.

Kruppa, J. Eurocodes - fire parts, proposal for a methodology to check the accuracy of assessment methods, CEN TC 250, Horizontal Group Fire, Document n 99/130, 1999.

Maraveas, C., Gernay, T. \& Franssen, J-M., Amplitude of local imperfections for the analysis of thin-walled steel members at elevated temperatures, ASFE'17, Manchester, UK, 2017.

Quiel, S. E., Garlock, M. E. M., Calculating the buckling strength of steel plates exposed to fire, ThinWalled Structures, 48(9), 2010, 684-695.

Xing, Z., Kucukler, M., Gardner, L., Local buckling of stainless steel plates in fire, Thin-Walled Structures, $148,2020,106570$. 